\title{
Mentoring as an Essential Element of Social Entrepreneurship
}

\author{
Artcer Tatiana $^{\mathrm{a} *}$, Chayka Yuliya ${ }^{\mathrm{b}}$, Trukhanenko Anna ${ }^{\mathrm{c}}$ \\ * Corresponding author: Artcer Tatiana, tv.arzer@gmail.com \\ ${ }^{a}$ National Research Tomsk Polytechnic University, 30,Lenina,Tomsk, Russia, tv.arzer@gmail.com, +73822606482 \\ ${ }^{b}$ National Research Tomsk Polytechnic University, 30, Lenina,Tomsk, Russia, y.chayka@yandex.ru, +73822606482 \\ ${ }^{c}$ National Research Tomsk Polytechnic University, 30, Lenina, Tomsk, Russia, truchanenko@sibmail.com, +73822606482
}

\begin{abstract}
http://dx.doi.org/10.15405/epsbs.2017.01.5

The changing age structure of the population could potentially have significant implications for economic development, labor markets and population welfare in countries with different levels of development. In this regard, there are questions related to possible labor shortages and lack of skilled workers, productivity and innovation, as well as the provision of adequate social protection and other services for the ageing population. Mentoring acts as a mechanism for the transfer of specific and important knowledge, experience, skills, techniques and methods of work, as well as the establishment of the corporate culture of an enterprise. The elderly people who have worked for one and the same company for many years have all the qualities of a mentor. Nowadays the government is actively implementing the policy strategies of supporting older people in their wellbeing; the role of business is also of high importance in this case. The article examines the possibility of using mentoring and engaging retired employees with their experience, high level of their education and professional qualification into training of young inexperienced workers. Mentoring is presented as an element of social entrepreneurship.
\end{abstract}

C) 2017 Published by Future Academy www.FutureAcademy.org.uk

Keywords: Ageing of population, mentoring, social entrepreneurship.

\section{Introduction}

Social entrepreneurship is an innovative activity originally aimed at solving or mitigation of social problems on the terms of self-sufficiency and sustainability. Social entrepreneurship is a balance of the social objectives and the commercial component, with the money being not a goal but a means to 
achieve these social aims, which allows entrepreneurs to remain stable and not dependent on the continuous donor initiative.

The term "social entrepreneurship" refers to the activities combining the features of social work and business. On the one hand, the main purpose of such an activity is the production of public goods, the solution of a social purpose. On the other hand, it has the characteristics of business - projects, that is it has to be commercially successful and profitable. Unlike any other business, social entrepreneurship doesn't have profit as the main objective but it is targeted at ensuring the sustainability of the social component, little dependence on sponsors and funders. In this article we focus on social entrepreneurship aimed at improving the well-being of older adults via mentoring in an enterprise.

The criteria of social entrepreneurship are:

- $\quad$ social mission;

- $\quad$ entrepreneurial approach;

- $\quad$ innovativeness (innovation in solving social problems, new combination of resources, new services for the region);

- $\quad$ replicability;

- $\quad$ self-sufficiency and financial sustainability.

Guided by these criteria social entrepreneurship can solve such social problem as a labor shortage by introducing mentoring by older adults in the workplace. The possibility of participation of older adults in the labor force could also help to reduce learning and training costs of young workers, increase the share of the intellectual property assets of the company, and improve the company's competitiveness in the market.

Mentoring is an effective and popular way to transfer professional knowledge and skills from a more experienced entrepreneur or specialist (mentor) to a less experienced one (protégé).

The effectiveness of mentoring lies in its individual character, as no any other form of training could be as targeted and close to real conditions. Mentor can respond quickly to the mistakes made by his protégé, investigate them thoroughly and guide to the correct course of work.

\section{The problem of skilled labor shortage}

Developed countries are now facing ageing population. About one third of the European population will have been over 60 years old by 2050 . According to the poll conducted among HR-directors of several large Russian companies, the ageing of personnel and the lack of young professionals in the market are the two most important issues. For example, the vast majority of HR directors recognize that the most critical factor today and in the near future is the staff shortage (this point of view was supported by nearly $80 \%$ of all respondents). Such shortage of qualified personnel is directly connected with the problem of ageing workforce: this factor was mentioned by the respondents in $38 \%$ of cases, and it has defined the traditional problem areas of Russian companies: a low level of staff motivation $38 \%$, and a low level of qualification - 33\%. The analysis also shows that the proportion of young workers (18-24 years old) and individuals aged 25-49 years is decreasing, and the proportion of the older generation of employees is increasing (Artcer et al., 2015). 
It is worth noting that such research has been conducted not only in Russia. In January 2, 2015 the German newspaper «Die Welt» published the article entitled "The demographic drama in Germany is becoming a reality." This article deals with Germany's economic problems associated with the generational change of working-age population. For example, the number of older workers, who relate to the citizens of above 50 years old in Germany accounted for 5.2 million people in 1999, by 2013 that number has increased up to 9.1 million. The proportion of elderly people among the employed increased during this time from 19 to $31 \%$.

Also, the experts of the Office for Budget Responsibility (OBR, UK) issued a report on July 11, 2015 predicting the size and structure of the population in 2065. The report reflects the evolution of the structure of the UK population over the past 50 years, in particular considering the additional increase in the number of people aged over 85 years compared to the quantitative increase in other age groups. It is this ageing population that will have the most significant impact on UK public finances in the long term (Harris, \& Jones, 2010).

In line with these changes in the population structure there is a need to explore the category of "older workers", its employment pattern and finding the best practice of the experience and knowledge transfer from the more qualified mature specialists to the younger workers of an enterprise.

\section{Mentoring as the way of overcoming the skilled labor shortage}

In modern conditions, the transfer of expertise to new employees is the main method of training within the firm, since no external training can prepare a novice for the professional activities in a particular company.

Let us consider the most popular methods of sharing experience in enterprises in Table 1.

Table 1. Comparative analysis of methods for the transfer of expertise in an enterprise.

\begin{tabular}{|c|c|c|}
\hline $\begin{array}{l}\text { The method of the } \\
\text { experience transfer }\end{array}$ & Advantages & Disadvantages \\
\hline Delegation & $\begin{array}{l}\text { 1. Delegating is an effective way of motivation; } \\
\text { 2. Delegating is an effective method to improve } \\
\text { the subordinates' skills. Performing unfamiliar } \\
\text { tasks stimulates an employee to master new } \\
\text { methods of work and study new areas of } \\
\text { activity. }\end{array}$ & $\begin{array}{l}\text { 1. The method of delegation is not } \\
\text { applicable to new employees as young } \\
\text { professionals do not have the required skills } \\
\text { and experience. }\end{array}$ \\
\hline $\begin{array}{l}\text { The internal system of } \\
\text { education (workshops) }\end{array}$ & $\begin{array}{l}\text { 1. Corporate training enables setting a clear task } \\
\text { to the problems that are to be solved in the } \\
\text { corporation; } \\
\text { 2. Qualified corporate training always facilitates } \\
\text { teambuilding } \\
\text { 3. Corporate events can be very cost-effective if } \\
\text { the company has its own premises for training. }\end{array}$ & $\begin{array}{l}\text { 1. There is no element of individuality; } \\
\text { 2. Poor feedback from employees; } \\
\text { 3. No possibility of running the gamut of } \\
\text { problems due to the lack of time. }\end{array}$ \\
\hline Mentoring & $\begin{array}{l}\text { 1. Staff training could be delivered directly at } \\
\text { the workplace; } \\
\text { 2. Individual attention to every employee helps } \\
\text { to take into consideration their personal } \\
\text { characteristics; } \\
\text { 3. Accelerating and simplifying the process of } \\
\text { adaptation of new employees; } \\
\text { 4. Effective way to raise the awareness of } \\
\text { corporate values and corporate culture among } \\
\text { trainee employees. } \\
\text { 5. Reducing staff turnover; } \\
\text { 6. Improving interpersonal interaction and } \\
\text { professional collaboration of workers. }\end{array}$ & $\begin{array}{l}\text { 1. Reduction of the performance efficiency } \\
\text { of a mentor; } \\
\text { 2. Unstructured information presentation } \\
\text { (knowledge, skills); } \\
\text { 3. Lack of pedagogical training methods. }\end{array}$ \\
\hline
\end{tabular}


These tables clearly reflect the benefits of mentoring over any other method of knowledge and experience transfer to young specialists.

The characteristic features of mentoring are presented in Figure 1.

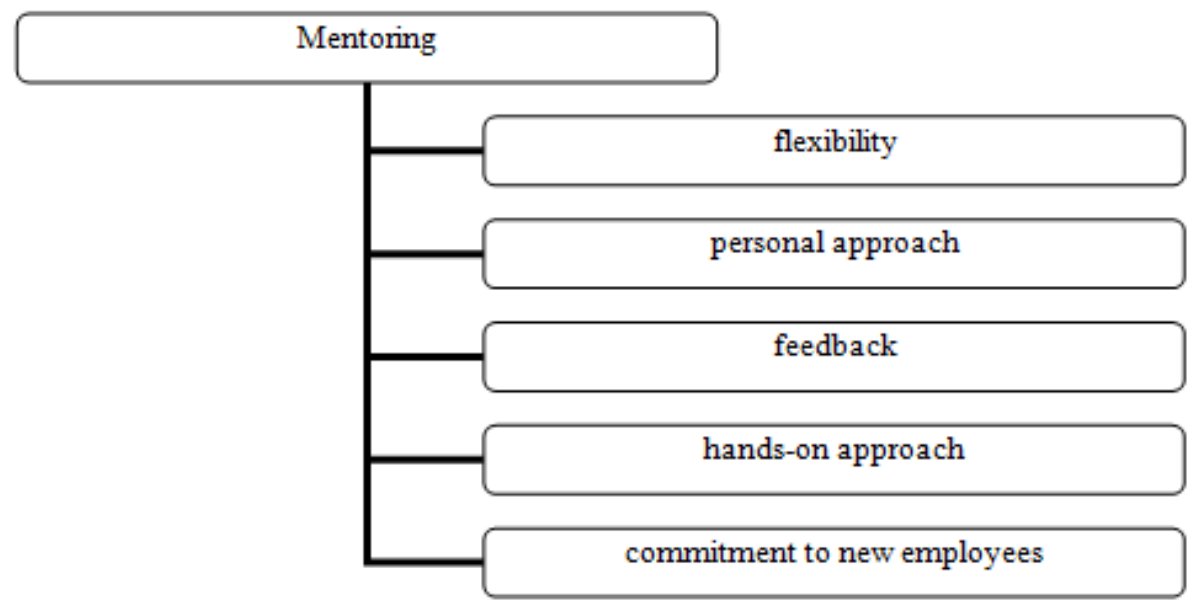

Figure 1. Characteristic features of mentoring.

On the basis of the significant advantages of mentoring it can be concluded that this method is the most effective in the formation of experience and competence for the professionals who have just joined the company. The efficiency of mentoring is that it has personal nature, and no other training method may be as targeted and close to the real conditions. A mentor can react quickly to the errors made by his team, and analyze these errors in detail, pointing out to the correct course of action..

\section{Mentoring is a necessary component of well-being of older adults}

Mentoring could also be considered as a necessary component of well-being of older adults. Since 2013 the International non-governmental organization HelpAge International in cooperation with the United Nations Population Fund (UNFPA) have launched the Global AgeWatch Index measuring the quality of life and wellbeing of older people around the world.

This index is based on a statistical analysis of the condition of the 13 indicators of a life standard and wellbeing of older people, combined in four main groups:

1. Financial security (sufficient level of income and the capability of using it independently to meet the basic needs in an older age). This group includes: the level of poverty in old age, GDP per capita, the scope of retirement income in relation to the well-being of older adults.

2. Health status (ageing is directly connected with the risk of ill health, physical weakness and disabilities). This unit includes mental wellbeing, life expectancy over 60 years and health condition.

3. Education and employment (education and employment are the elements that contribute to the ability of overcoming problems and characterize the abilities of older people).

4. Good social life conditions (elderly citizens should have freedom of choice, lead an independent and responsible life). The unit reflects the physical safety, social connectedness, civil liberties and access to public transport. 
The third set of indicators - education and employment includes active life of citizens over 60 years old. This indicator is closely linked with mentoring, as mentoring system can help senior citizens to adapt to the psychological aspect of retirement. Retirement is a multi-stage social event and a social process. It consists of several phases: a decision-making stage of employment termination, the stage of preparation for leaving the job, and the stage of adapting to new social roles (Fund, 2010).

For the majority of senior citizens the retirement is accompanied by many lifestyle changes and the forced necessity of breaking the usual ties, they experience a new attitude from their associates and the need to organize their time in a new way. Retirement may also mean giving up all the important, valuable and productive things in life. Due to these issues a significant number of people are forced to continue working after their retirement.

However, these older people, who are still full of energy and wish to work, face numerous obstacles. Their social environment (including businesses) does not always provide adequate conditions for adaption to these changes. According to the Russian polls, $32.5 \%$ of all pensioners are in instant need of working for economic or psychological reasons. But it should be noted that most of them require the individual working pattern (flexible working hours, part-time job, the proximity to the place of residence, etc.) but such conditions are difficult to implement in the contemporary situation, or it simply requires greater effort from the employers and, consequently, they have little or even no interest.

If a system of mentoring is built correctly, all the important skills and experiences will remain within the company, and will be transferred "from generation to generation" to new employees. It will make the newcomers' integration into the team easier, as well as help HR-managers to reduce the staff training costs.

\section{Conclusion}

Many businesses are in need of the effective ways of solving such problems as the unique knowledge preserving and overcoming the skilled labor shortage. There are a lot of young inexperienced employees and, at the same time, many long-service employees, who are going to retire soon. Often, when leaving a company, such honored workers take their unique knowledge and experience with them.

For many retired people, in turn, it is very important to be "socially important people". Retired people with higher education, $\mathrm{PhDs}, \mathrm{ScD}$, experts with the experience of more than 25-30 years comprise a cross-functional fund of professionals who can help to improve the workforce resource efficiency of an enterprise.

Mentoring acts as a mechanism for the transfer of specific and important knowledge, skills, techniques and methods of work, as well as the establishment of the corporate culture of an enterprise. The elderly people who have worked for one and the same business for many years have all the qualities of a mentor. Nowadays the government is actively implementing the policy strategies of supporting older people in their wellbeing; the role of business is also of high importance in this case. It is an enterprise that can not only achieve its own goals by introducing mentoring but also maintain social policies of the country as a whole, see Figure 2. 


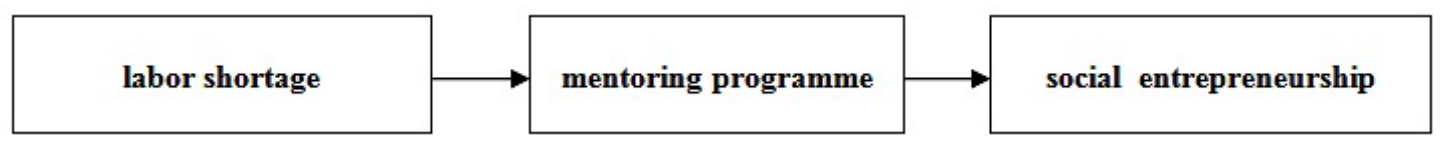

Figure 2. The general scheme of process

Mentoring system is a necessary unit of a corporate culture of a firm. For this process to continue in a proper way it is necessary to keep up the regular interest to this issue of firm executives. If the introduction of mentoring is not put under control, the process will not give the desired effect. Proper mentoring system construction results in preserving all the important knowledge and skills within the organization. Furthermore, such cooperation in a company strengthens team spirit and corporate culture. As a consequence, a company acquires a highly professional and motivated team of employees that share its values and culture.

\section{References}

Artcer, T.V., Galiegue, X, \& Mondello, G. (2015), Mentoring as a way of forming and effective utilization of manpower (the experience of France). Procedia - Social and Behavioural Sciences. 53-57

Fund, Z. (2010). Effects of communities of reflecting peers on student-teacher development - including in-depth case studies Teachers \& Teaching, 16(6), 679-701.

Harris, A., \& Jones, M. (2010). Professional learning communities and system improvement. Improving Schools, 13(2), 172-181. 